\title{
DEFICIENCIA DE VITAMINA B12 EN PERSONAL DE SALUD QUE APOYA ANALGESIA DEL PARTO CON OXIDO NITROSO EN HOSPITAL TIPO 2 Y DESARROLLO DE POLÍTICAS PUBLICAS
}

\author{
Fernando González Cabrera ${ }^{1}$, Sebastián Mela Sfeir ${ }^{2}$, Rodrigo Navarro González ${ }^{2}$ \\ Anestesiólogo Hospital Las Higueras. \\ 2 Residente Anestesiología Universidad Andrés Bello, Hospital Las Higueras.
}

\begin{abstract}
Introducción: A raíz de un caso severo de déficit de vitamina-B12, conociendo que la paciente trabaja como Matrona de partos, y haciendo debida cuenta de la relación que existe entre el oxido nitroso y la inactivación permanente de esta por oxidación de cobalamina, se realiza muestreo voluntario del personal en riesgo.
\end{abstract}

Objetivo General: Estimar prevalencia de déficil de Vitamina B12, en una población eventualmente en riesgo, como es el caso del personal de matronas de parto, expuesa al oxido nitroso.

Material y Métodos: Se investigara la incidencia de déficit de vitamina B12 en el personal de salud que apoya la función de la analgesia del parto en el hospital, la que es entregada con oxido nitroso con el sistema MEDIMIX-50 de , solicitándose niveles de vitamina B12 y comparándola con la de la literatura en la población general. Cabe destacar que investigando en terreno la sala de parto carece de todo sistema de recambio de aire pues la sala de partos es una adaptación de una sala común del mencionado hospital.

Resultados: Se obtienen resultados de niveles de vitamina B 12 en 14 personas que laboran en la maternidad del mencionado Hospital y que tengan relación directa con el apoyo a la analgesia del parto administrada con oxido nitroso. Todas correspondientes a un cuarto turno y 2 personas reemplazantes. Todas de sexo femenino y de edad promedio de 41,8 años. Un total de 6 personas de las catorce presentaron niveles bajo lo normal de vitamina B12 lo que para el grupo en estudio representa un $42,85 \%$, lo que comparado con la población general (prevalencia de déficit de vitamina B12 entre 3,5 y 7,5\% dependiendo del grupo etario estudiado representa un incremento cercano a diez veces superior a la población general.

Conclusiones: Si bien la primera causa de déficit de vitamina B12 es la falta o disminución de factor intrínseco, seguido de gastrectomías y recientemente relacionada a inflamación crónica de la mucosa gástrica y/o su asociación al uso persistente de bloqueadores de la bomba de protones; de asociarse este grupo muestral con déficit de vitamina B12 a un aumento de homocisteina en sangre seria consistente con un déficit funcional de esta y plausiblemente causado porl oxido nitroso. De ser así parece interesante considerar este como caso centinela e inicial; caso que no deberíamos dejar pasar y deberíamos profundizar en la búsqueda de la causa primera de este hallazgo, con miras a buenas practicas en nuestras políticas de salud. 